longer christened a "have not" province. The New Brunswick government agrees that one of the most important components of self-sufficiency is the province's relationship and position within the federal nation-state.

This book provides some thoughtful and important insights into New Brunswick's new policy direction to achieve self-sufficiency. Two areas that were not discussed were New Brunswick's past provincial policies that were designed to stimulate growth, and an analysis of the impact of federal policies and institutions on the province (there is a well developed body of literature in this area). Including an analysis of why provincial development policy failed in the past and an examination of the province's underdevelopment in relation to its position within the federation, would have made his volume stronger. While this is an area that could have been explored further, this work is an excellent and thorough compilation that will be widely appreciated among the academic community and will hopefully find its way to provincial policy analysts and decision makers.

Adrian Egbers Dalhousie University

\title{
Max Foran, Ed. Icon, Brand, Myth: The Calgary Stampede (Edmonton: AU Press, 2008).
}

The Calgary Stampede is one of western Canada's most popular cultural festivals, and a book like Icon, Brand, Myth: The Calgary Stampede has been much anticipated. Icon, Brand, Myth is a compilation of essays that explore the cultural significance of one of the longest-running western entertainments in North America from its founding as an agricultural exhibition in the 1880s until the present. While the literature on American rodeos and frontier day festivals is relatively rich, a consideration of Canada's grand celebration of western culture has been neglected. Recently, the Calgary Stampede has received more academic attention and, as divulged in the introduction, this book is the product of a course on the Calgary Exhibition and Stampede formerly offered by University of Calgary's Faculty of Communication and Culture. Each of the books' contributors were either lecturers or "the subject of reference" in Stampede courses offered from 2004-2006 (ix).

The collection opens with an overview of Stampede history and Max Foran, the book's editor, provides the historical context for its origin and evolution. As one might expect, chapters include topics such as the establishment of the agricultural exhibition, the rodeo, cowboys, and the famous chuckwagon race. The book, however, moves beyond what might be considered traditional Stampede fare and other chapters explore the midway, parading culture, Calgary's public monuments, the Stampede's relationship with the city, the Stampede's role 
in promoting western art, and Hugh Dempsey provides the first comprehensive overview of First Nations peoples' contribution to the Stampede.

While each chapter considers a specific aspect of the Calgary Stampede and Exhibition, analyses reach beyond the history of the rodeo and explore the place of the Stampede in shaping identity based on a collective memory of "the West". Drawing on theoretical frameworks popularized by Eric Hobsbawm, Stuart Hall, and Benedict Anderson, authors connect the Stampede to the creation of local, regional, and national identities, as well as the articulation of a "modern" identity while drawing on shared attitudes about western heritage. For example, Glen Mikkelsen's assessment of the rodeo concludes that it "...has played, and continues to play, a pivotal role in preserving and propagating what the West is perceived to be." (206) Similarly, Aritha van Herk's claims that the chuckwagon races are Calgary's own, part history and part technology, "born and bred in the West.” (237) Calgary Stampede's Chief Executive Officer, Vern Kimball, reflects that "[p]eople want to protect Calgary's unique spirit and identity," and they see the Calgary Stampede as a representative of their community values and character (334). These chapters link the Stampede rodeo events to the creation and maintenance of a local and regional identity.

More broadly defined national and "modern" identities are explored in Lorry W Felske's chapter on Calgary's parading traditions that highlight the tensions between modernity and heritage, and between expressions of the American and Canadian West. Tamara Palmer Seiler continues to explore these tensions in her examination of the cowboy in the Calgary Stampede and in her joint chapter with Robert M Seiler that considers the Stampede posters as sites of struggle over the meaning of the Western Canadian experience (314). She reflects that there is an inherent tension "...in a Canadian city and region using what is arguably an American cultural icon as its defining symbol.” (176) Both national and "modern" identities were reaffirmed and subverted through the use of icons such as the cowboy.

Analysis throughout the book would have been enhanced if the authors had further problematized the construction of local, regional, national, and "modern" identities by considering class, race, and gender. Max Foran's reflection on the Stampede's relationship with the city leaves the reader with some interesting questions that address race and class, but very few of the articles explicitly tackle what these important categories mean to the construction of identity.

The weakest aspect of the book, however, is its nature as a compilation of essays. There are noticeable gaps in parallels that could have been drawn between chapters. For example, Fiona Agnus explains that the midway never really reflected the "myth of the Wild West, combined with contemporary notions of what constitutes social and technological progress." (112-13) Instead, she focuses on the midway's evolution based on social constructions of 
respectability without connecting it to changes rodeo faced that were dictated by similar ideals briefly outlined by Donald G Wetherell (24-27). This is not a problem unique to this edited collection but this popular format could be strengthened if authors were encouraged to work in concert with one another, especially when contributors have already participated in implementing the same focused course.

Icon, Brand, Myth would be of interest to professors and students of cultural studies or Canadian Studies. This book is a great beginning for a more thoughtful consideration of the Calgary Stampede and its place in Western Canadian culture.

Susan L. Joudrey

Carleton University

\section{Andrew Parnaby, Citizen Docker (Toronto: University of Toronto Press, 2008).}

Citizen Docker is framed chronologically by the Vancouver waterfront strikes of 1923 and 1935. While the story of the strikes has been told before, Andrew Parnaby's analysis of the context from which the strikes emerged is anything but familiar. Drawing from a variety of sources, the most important of which are the extensive papers of the Shipping Federation of British Columbia, Parnaby explores the aggressive efforts of waterfront employers to end the system of casual work on Vancouver's waterfront. Following the trauma of the 1923 strike, shippers developed a system of welfare capitalism that aimed to change the social makeup of the longshoring workforce and alter the culture of work on the docks. In Parnaby's words, "the Shipping Federation hoped that by weeding out the foreign-born and the radical, recruiting white married men, and promoting middle-class values of discipline, sobriety, and thrift, it could shape a new, more compliant working-class identity." (12) The Shipping Federation sought in particular to bolster the workingmen's role as breadwinners, and thus as "citizens." In important ways the Federation succeeded. By the early 1930s, 70 percent of Vancouver's dock workers were married men. "Welfare capitalism and labour market reform called into being new workplace habits, disciplines, and incentives," Parnaby concludes; in the end these changes "remade the everyday texture of working life on the waterfront." (163)

Yet the creation of a shared understanding of citizenship was never complete, nor did longshoremen embrace their role as breadwinners simply because of the coercive power of employers, and it is primarily in Parnaby's discussion of the diverse routes through which capital and labour embraced the idea of citizenship that this book's contribution to Canadian working class historiography is to be found. The story of one longshoreman, Ivan Emery, illus- 